\title{
Elementos para começar uma conversa sobre a formação de formadores de leitores críticos de textos literários para atuação no Ensino Médio
}

\section{RESUMO}

Rodrigo Alves dos Santos ralves.professor@gmail.com Centro Federal de Educação Tecnológica de Minas Gerais, Divinópolis, Brasil.
Neste ensaio, parte-se da apresentação do contexto das reorientações sobre a abordagem do texto literário nos discursos reguladores do ensino de Língua Portuguesa do Ensino Médio brasileiro dos anos 1990 para tratar emergência do formador de leitores críticos de textos literários, posição de sujeito a ser ocupada por professores de Língua Portuguesa do Ensino Médio atual. Na sequência, defende-se o argumento de que a denominação ensino de literatura não se alinha com as demandas atuais para a abordagem do texto literário nos anos finais da educação básica do Brasil, apostando na denominação trabalho com a leitura literária para isso. Finalmente, em um último tópico, elencam-se, com base em alguns autores cuja leitura integral este texto não dispensa, seis excessos que, a nosso ver, contribuem para distanciar, na escola de nível médio, o leitor jovem do texto literário. Trata-se de um texto cujo objetivo central é apresentar, de forma acessível, um painel das tensões que hoje atravessam a abordagem do texto literário em sala de aula para, com isso, estimular discussões em cursos de formação continuada de professores de Língua Portuguesa para o trabalho com a leitura literária no Ensino Médio.

PALAVRAS-CHAVE: Formação de Professores. Língua Portuguesa. Formação de Leitores. Ensino Médio. 


\section{INTRODUÇÃO}

O presente texto tem uma intenção bastante pretensiosa - dirão alguns - ou até inalcançável - dirão outros: apresentar a professores de língua portuguesa em efetivo exercício no ensino médio há pouco ou há muito tempo, de forma acessível, um painel das tensões que hoje atravessam a abordagem do texto literário em sala de aula.

Não se trata de uma empreitada que teve sua origem em uma vontade deliberada da autoria destes escritos. Trata-se de uma tarefa encomendada, já há vários anos, por alunos em final de cursos de licenciatura em Letras, por professores iniciantes na docência e até por professores experientes que atravessaram nosso caminho em cursos de extensão, de formação continuada, em encontros esporádicos em congressos realizados nos mais diversos cantos do país. Em comum, esses diferentes sujeitos tinham a alegação de que "desejavam sim fazer uma reflexão crítica sobre a abordagem dos textos literários em salas de aula do Ensino Médio", mas se esbarravam na falta de condições para realização de uma leitura detida sobre as longas discussões acadêmicas sobre o tema, fosse isso por causa de limitação de tempo ou de capital financeiro para aquisição de livros, ou mesmo por dificuldade de entendimento do vocabulário empregado por certos autores que discutem a questão da abordagem do texto literário em contexto escolar no Brasil.

Diante desse quadro, finalmente optamos por tentar atender a essa demanda há anos a nós apresentada e cada vez mais urgente em um país que, como se sabe claramente, vive às voltas com a dificuldade de acertar uma fórmula que torne o ensino de nível médio realmente interessante e útil para um público jovem cada vez mais confrontado com condições de existência assoladas por largo quadro de instabilidade (BACHA; SCHWARTZMAN; 2011).

Almejando alcançar o objetivo a que se propõe, o presente texto assim se apresenta. Inicialmente, expomos rapidamente as mudanças na configuração da educação básica brasileira nos anos finais da década de 1990, evidenciando o contexto das reorientações sobre a abordagem do texto literário nos discursos reguladores do ensino de Língua Portuguesa de nível médio brasileiro. Em um momento seguinte, tratamos da emergência do formador de leitores críticos de textos literários, posição de sujeito a ser ocupada por professores de Língua Portuguesa do Ensino Médio que desejam se alinhar com as demandas atuais da educação básica brasileira. Posteriormente, passamos a um item no qual defendemos o argumento de que a denominação ensino da literatura não se alinha com as demandas atuais para a abordagem do texto literário nos anos finais da educação básica do Brasil, insistindo na denominação trabalho com a leitura literária para isso. Finalmente, em um último tópico, refletimos, com base em alguns autores cuja leitura integral este texto não dispensa, seis excessos que, a nosso ver, contribuem para distanciar, na escola de nível médio, o leitor jovem do texto literário.

Não nos restam dúvidas das muitas possibilidades de que a crítica considere o presente texto como algo reducionista em relação a uma questão complexa e pelo menos no Ocidente - muito pertinente: a presença/ausência da literatura na formação do jovem em contexto escolar. Também não desconhecemos a probabilidade considerável de um texto como este ser acusado de, apesar de não elencar prescrições pedagógicas para os professores aos quais se destina, ser 
acusado de apresentar receitas para lidar com uma situação sempre contingente e inusitada, atravessada por inúmeros fatores, como a formação do leitor jovem. Resta-nos reconhecer, ainda, que o leitor potencial deste texto - anunciado no início deste tópico - poderá se decepcionar ao não encontrar aqui prescrições de como agir em sala de aula quando da abordagem do texto literário. Trata-se de uma opção nossa não o fazer, pois entendemos que, assim, o texto fica coerente em relação a um título que anuncia "elementos para começar uma conversa...". Estamos considerando que, estimulando um começo de conversa, seu desenvolvimento se dará a partir da introdução de um momento de prática de elaboração de sequências pedagógicas e materiais didáticos que possam se apoiar nas discussões aqui propostas.

Assim, a opção por correr todos esses riscos, e muitos outros aqui não elencados, considera a possibilidade de que estes escritos sirvam mesmo como ponto de partida para momentos de formação docente realizados dentro e fora dos espaços oficiais de constituição da profissão - tanto dos professores iniciantes quanto dos experientes.

\section{MUDANÇAS NA CONFIGURAÇÃO DA EDUCAÇÃO BÁSICA BRASILEIRA NOS ANOS FINAIS DA DÉCADA DE 1990: O CONTEXTO DE EMERGÊNCIA DE REORIENTAÇÕES SOBRE A ABORDAGEM DO TEXTO LITERÁRIO NOS DISCURSOS REGULADORES DO ENSINO DE LÍNGUA PORTUGUESA DE NÍVEL MÉDIO}

A educação básica no Brasil ganhou contornos bastante complexos nos anos posteriores à Constituição Federal de 1988" (CURY, 2002, p.170). Assim, aspectos como a ampliação do conceito de cidadão, incluindo nesta noção sujeitos anteriormente dela excluídos (DUARTE, 2008) e a extensão da educação formal, como um direito, a parcelas anteriormente excluídas da escola regular constituíram algumas ações que vieram contribuir para uma reconfiguração da Educação Formal em todo o país, com todos os conflitos inerentes a esse tipo de mudança.

No que se refere ao modo como se passou a compreender, na Constituição Federal de 1988, a Educação Formal, um novo entendimento, entre os tantos por ela instaurados, veio a interferir de forma mais incisiva na compreensão e configuração das instituições formais de ensino nacionais. Trata-se do conceito de Educação Básica, o qual foi adotado pela Constituição Federal pressupondo a congregação e a articulação da Educação Infantil, do Ensino Fundamental e do Ensino Médio.

Para os interesses desta reflexão, a novidade a ser posta em foco ali é a inclusão do Ensino Médio como parte integrante da Educação Básica. Tratava-se de um ato que, segundo o próprio discurso oficial, viria a tornar possível o acesso a graus mais altos de instrução a uma considerável parcela da população que, até então, era estimulada a concluir - obrigatoriamente - apenas o Ensino Fundamental. Tal mudança permitiria, ainda, conforme discute Cury (2002, p.183), enfatizar a vertente formativa dos anos finais da (então, nova) Educação Básica, colocando em segundo plano (mas não desconsiderando) suas funções propedêutica e profissionalizante.

Nestes termos, ao fazer uso da noção de Educação Básica já mencionada, o discurso regulador da educação formal do país estava, assim, propondo um 
entendimento que dizia respeito ao desejo de maior integração entre suas etapas. Não é de surpreender, portanto, que um passo inevitável desses movimentos ocorridos no final dos anos 1980 e na primeira metade da década de 1990 fosse a oficialização de uma nova Lei de Diretrizes e Bases da Educação Nacional (LDBN) - Lei 9394/96 -, já que a LDBN anterior se tornara, com a promulgação da Constituição de 1988, "ultrapassada" em muitos aspectos.

Com a configuração da Lei 9394/96, estavam dadas, aos olhos dos legisladores de então, as condições necessárias para a elaboração de documentos como os Parâmetros Curriculares Nacionais (PCN), uma das publicações mais importantes na trajetória recente da educação brasileira, tendo em vista o seu efeito (re)direcionador não só das funções e das configurações das etapas da educação básica, mas também de suas fundamentações teórico-metodológicas de pilares como ensino, aprendizagem e avaliação.

Sendo um dos primeiros resultados mais expressivos da operacionalização dos entendimentos acerca da "nova" configuração da educação formal no país pós-constituição de 1988, os PCN constituíram um marco na movimentação que objetivava a reconfiguração da educação no Brasil. Isso porque se tratavam de alguns dos primeiros documentos destinados a uma diversidade de profissionais atuantes na educação formal, intencionando orientar a materialização dos novos conceitos que passariam a sustentar a noção de educação básica legitimada pela Constituição Federal de 1988.

Como toda materialização de uma posição oficial em relação à educação de um país, a implementação dos PCN não foi (nem vem sendo, quase duas décadas depois de seu aparecimento) pacífica, reunindo, consequentemente, grupos pró e grupos contra a sua oficialização:

[...] o primeiro deles defendia (e defende) a necessidade de se criarem parâmetros nacionais, visando garantir um mínimo de qualidade para todas as escolas brasileiras. Esse argumento é fruto, entre outros motivos, de avaliações sobre o desempenho dos alunos e das disparidades regionais e socioeconômicas demonstradas pelas pesquisas e avaliações sobre essas escolas. A segunda posição lança dúvidas sobre a necessidade desses parâmetros, e previne contra os riscos políticos e culturais da sua criação, particularmente porque é necessário, segundo essa corrente, respeitar a diversidade cultural e a autonomia dos estados, municípios ou comunidades, no processo de definição dos seus conteúdos e práticas escolares (MARINHO, 2007, p. 171) ${ }^{1}$

Logo, o aparecimento dos Parâmetros Curriculares Nacionais, talvez pelo seu maior alcance em relação às leis e aos decretos específicos que foram publicados para a regulação dos novos entendimentos sobre a educação formal, deu visibilidade aos estranhamentos, às concordâncias, às discordâncias e às ressonâncias geradas pelas compreensões de educação formal que passaram a vigorar no país na última década do século XX. Assim sendo, concomitante a todo esse processo, instaurou-se toda uma movimentação de práticas discursivas e não discursivas no sentido de buscar reajustar não só o sistema educacional então vigente, mas também seus documentos reguladores, já que um dos frutos do intenso debate em torno dos Parâmetros Curriculares Nacionais foi a constatação da enorme quantidade de contradições que eles apresentavam. 
Nestes termos, apesar de a existência de referenciais curriculares não ser exatamente uma novidade para a educação formal do Brasil (CURY, 1996), a oficialização dos PCN nesta função apresentou peculiaridades. Entre elas, um destaque necessário deve ser dado ao fato de que os debates acerca dos Parâmetros não só precederam sua construção e publicação, mas também continuaram após tal momento. E foi exatamente essa continuidade desses debates que veio a oportunizar uma intensa revisão dos Parâmetros Curriculares Nacionais, confirmando um dinamismo no processo de operacionalização dos novos entendimentos acerca da educação básica no país que, passadas cerca de duas décadas depois dos PCN, ainda está longe de terminar.

Diante disso, no que se refere ao ensino de Língua Portuguesa, todo o desdobramento gerado com a publicação dos Parâmetros Curriculares Nacionais do Ensino Médio (PCNEM) e de documentos dele derivados colocou em circulação uma série discussões e reflexões que - mesmo ainda ancoradas em velhos debates do universo acadêmico (Cf. SANTOS, 2014) - reorientou a finalidade do ensino de língua materna nos anos finais da educação básica nacional, em particular no que dizia respeito à abordagem dos textos literários.

\section{DA EMERGÊNCIA DO FORMADOR DE LEITORES CRÍTICOS DE TEXTOS LITERÁRIOS}

Segundo o discurso oficial veiculado em publicações como os Parâmetros Curriculares Nacionais de Língua Portuguesa do Ensino Médio (PCNEM-LP) e seus derivados como os PCN+ (BRASIL, 2002) e as Orientações Curriculares para o Ensino Médio (BRASIL, 2006), desde finais dos anos 1990, as instituições de ensino deste país vêm sendo chamadas a integrar um ousado projeto educacional. Projeto este que almeja contribuir para a transformação da escola regular de nível médio em um espaço capaz de "promover a realização pessoal, a qualificação para um trabalho digno, para a participação social e política, enfim, para uma cidadania plena da totalidade de seus alunos e alunas" (BRASIL, 2002, p. 10).

Esse "preparo para o exercício da cidadania" (BRASIL, 1999, p.15), passou, assim, a ser uma das finalidades mais associadas à instituição escolar, sobretudo com a incorporação, pelos discursos oficiais e acadêmicos, dos princípios estabelecidos pela Constituição de 1988 e pela Lei de Diretrizes e Bases da Educação Nacional, de 1996. Nesse sentido, também à abordagem da literatura em espaço escolar - portanto carregada de intencionalidades postas a serviço do projeto maior de educação formal engendrado pelo discurso oficial ao sabor das épocas e das vontades de poder/saber que configuram as disciplinas escolares foram impostas alterações alinhadas a esse novo projeto.

Especificamente no que se refere à abordagem do texto literário nas aulas de Língua Portuguesa dos anos finais da educação básica brasileira, documentos como os Parâmetros Curriculares Nacionais do Ensino Médio de Língua Portuguesa (BRASIL, 1999), os PNC+ de Língua Portuguesa (BRASIL, 2002) e as Orientações Curriculares para o Ensino Médio - OCNEM de Língua Portuguesa (BRASIL, 2006) alicerçaram a emergência do formador de leitores críticos de textos literários, posição de sujeito a ser ocupada hoje por qualquer professor de 
língua materna que queira estar em consonância com as demandas atuais para o projeto educacional de formação de nível médio no Brasil (SANTOS, 2009).

Nesse movimento, o professor de Língua Portuguesa do Ensino Médio, quando da abordagem do texto literário, deve abandonar velhas práticas e convicções assentadas nos entendimentos que fundamentavam a ação deste docente no antigo Segundo Grau, quando:

1) o que se pretendia, no trato com o texto literário na disciplina de Língua Portuguesa de então, era a transmissão de um saber legitimado sobre uma literatura canônica; 2) um foco seria dado à literatura como sinônimo de identidade nacional e como modelo de emprego da língua materna; 3) em termos de método - uma fidelidade à historiografia literária seria manifestada, assim como demonstrar-se-ia uma preferência por abordagens estruturalistas; e, principalmente, 4) a compreensão de aluno era a de mero receptor do saber "superior" que era a literatura. (SANTOS, 2009, p.160)

Assim sendo, ocupar a posição de formador de leitores críticos de textos literários, passa a exigir, conforme argumentação oficial, que o professor de Língua Portuguesa seja, no que se refere ao trabalho com a leitura literária, "mais consciente sobre o público para o qual leciona - os jovens -, mais bem informado, atualizado, usuário competente das tecnologias, leitor não preconceituoso ${ }^{2} . . . "$ (SANTOS, 2014, p.436). Nesse deslocamento, o professor passa, ainda, à condição de mediador de leitura: "alguém que toma o texto como um monumento que precisa ser explorado, olhado, analisado, desconstruído se necessário" (BERTUCCI BARBOSA, J.; VIEIRA BARBOSA, M. , 2013, p.11).

Passa-se, com isso, a demandar um ajustamento entre as posições de professor e de aluno convencionadas pela estrutura escolar, colocando ambos, nas aulas de Língua Portuguesa, quando leitores de um texto literário, numa situação que exigiria minimizar o distanciamento tão cristalizado entre docente e discente. Isso, contudo, sem desconsiderar o potencial do docente para ser um leitor mais experiente e, por isso, conduzir os processos de negociação dos sentidos de um texto $(\mathrm{KOCH}, 2009$, p.17), reconhecendo que esse texto tem seus direitos e impõe limites à interpretação (ECO, 2008).

Todo esse quadro de mudanças sumarizado nos dois parágrafos acima fundamenta um deslocamento que consideramos central no que se refere à abordagem do texto literário nas aulas de Língua Portuguesa do Ensino Médio: a minimização do ensino da literatura para dar lugar à formação de leitores críticos de textos literários. Formação esta que passa a demandar a adoção de estratégias que estimulem o aluno a "discutir ideias, expor interpretações individuais e partilhar das experiências geradas pela incursão nos textos, em suma, a alcançar o adentramento crítico da leitura feita (UCHÔA, 1991, p.76)".

\section{DO ENSINO DE LITERATURA AO TRABALHO COM A LEITURA LITERÁRIA NAS AULAS DE LÍNGUA PORTUGUESA DO ENSINO MÉDIO}


Houve um tempo em que não se estranharia, entre os estudiosos da escolarização da literatura brasileiros, o emprego da expressão ensino da literatura como sintetizadora da abordagem do texto literário em contexto escolar. No entanto, essa denominação veio, sobretudo a partir dos anos 1990, se tornando um tanto descabida, quando se pensa nas expectativas geradas pelos documentos oficiais quanto à abordagem e o trato do texto literário em sala de aula, particularmente no contexto do Ensino Médio. Isso porque não se deve esquecer que esse nível de escolaridade se volta, majoritariamente, para a formação dos jovens, ou seja, de leitores com algum contato pregresso com gêneros e produções típicas da esfera literária, seja nos anos anteriores de escolarização, seja em sua existência fora dos espaços formais de educação.

A palavra ensino é um desses termos que os usuários da língua que o empregam raramente refletem sobre seu significado originário e sobre toda a carga semântica que o cerca, quando a questão é a perpetuação do saber acumulado por gerações e gerações de seres humanos. Em sua origem remota, a palavra ensinar, da qual temos ensino, resgata in+signare que, no latim, remete a marcar com um sinal, pôr um sinal. Entre nós, esse verbo chegou com o sentido de "transmitir conhecimento", conforme assinala Cunha (2001, p.301). Tanto em um quanto em outro sentido, ensinar pressupõe, na sua origem, uma passividade do sujeito que é efeito da ação (aquele que aprende), algo que, para os dias atuais, configura-se como um entendimento deveras datado, tendo em vista o (hoje) consensual entendimento de que a aprendizagem ocorre de forma significativa quando o aprendiz - partindo daquilo que já conhece - atua, constrói/desconstrói/reconstrói o seu saber de forma participativa e atuante. (AUSEBEL ET. AL., 1980; MOREIRA, MASINI, 1982).

No Brasil, como em grande parte do mundo Ocidental, tornou-se recorrente associar essa acepção originária de ensino (com o aluno ocupado uma condição de passividade) às chamadas pedagogias tradicionais. Pedagogias estas que, como defende Giroux (1997), tomam a instituição escolar como mero local de instrução cujo objetivo central é a transmissão de um conhecimento instrumental para a sociedade existente (GIROUX, 1997, p.148). Nesse âmbito, são provenientes do Brasil contribuições mundialmente respeitadas como as de Paulo Freire, para quem o diálogo ocuparia uma centralidade nas chamadas pedagogias críticas e libertadoras, aquelas que estariam na posição oposta às pedagogias tradicionais. De acordo com Freire (1987, p.45), essa condição dialógica do processo de aprendizagem "não pode reduzir-se a um ato de depositar ideias de um sujeito no outro, nem tampouco tornar-se simples troca de ideias a serem consumidas pelos permutantes". É nesse âmbito que o mais reputado educador brasileiro defende ser papel da educação "exercitar processos de emancipação individual e coletiva, estimulando e possibilitando a intervenção no mundo" (MOREIRA, 2010, p.146).

É nessa esteira da defesa de uma educação para a emancipação humana que se destaca, quando se fala sobre ensino, o nome do filósofo e educador brasileiro Dermeval Saviani. Distinguindo Teorias Não Críticas (Pedagogias Tradicional, Nova e Tecnicista), Teorias Crítico-Reprodutivistas (Teoria do Sistema de Ensino Enquanto Violência Simbólica, o Aparelho Ideológico do Estado, Teoria da Escola Dualista) de sua Pedagogia Histórico-Crítica, Saviani $(1999,2008)$ parte da compreensão do homem como ser concreto, ao mesmo tempo em que 
propõe uma educação que valoriza a assimilação do saber produzido historicamente.

No escopo da Pedagogia Histórico-Crítica, Saviani (1999) propõe uma acepção de ensino diferente daquela incutida no termo originário. Sob esse novo prisma,

[...] uma pedagogia articulada com os interesses populares valorizará, pois, a escola; não será indiferente ao que ocorre em seu interior; estará empenhada em que a escola funcione bem; portanto, estará interessada em métodos de ensino eficazes. Tais métodos se situarão para além dos métodos tradicionais e novos, superando por incorporação as contribuições de uns e de outros. Portanto, serão métodos que estimularão a atividade e iniciativa dos alunos sem abrir mão, porém, da iniciativa do professor; favorecerão o diálogo dos alunos entre si e com o professor, mas sem deixar de valorizar o diálogo com a cultura acumulada historicamente; levarão em conta os interesses dos alunos, os ritmos de aprendizagem e o desenvolvimento psicológico, mas sem perder de vista a sistematização lógica dos conhecimentos, sua ordenação e gradação para efeitos do processo de transmissão-assimilação dos conteúdos cognitivos. (SAVIANI, 1999, p. 79)

Nesse âmbito, conforme continua o autor,

[...] se fosse possível traduzir os métodos de ensino que estou propondo na forma de passos à semelhança dos esquemas de Herbart e de Dewey, eu diria que o ponto de partida do ensino não é a preparação dos alunos cuja iniciativa é do professor (pedagogia tradicional) nem a atividade que é de iniciativa dos alunos (pedagogia nova). O ponto de partida seria a prática social (10 passo), que é comum a professor e alunos. Entretanto, em relação a essa prática comum, o professor assim como os alunos podem se posicionar diferentemente enquanto agentes sociais diferenciados. $\mathrm{E}$ do ponto de vista pedagógico há uma diferença essencial que não pode ser perdida de vista: o professor, de um lado, e os alunos, de outro, encontram-se em níveis diferentes de compreensão (conhecimento e experiência) da prática social. (SAVIANI, 1999, p. 79-80)

A despeito de toda essa contribuição de teóricos da educação nacionais e internacionais para a superação das concepções de ensino fundadas nos pressupostos da passividade do aluno, poucos são os espaços escolares que incorporaram tais propostas quando da abordagem do texto literário, em particular no ensino médio. A esse respeito, não são poucos os estudiosos que vêm tomando como objeto de estudo a abordagem do texto literário nas aulas de Língua Portuguesa dos anos finais da educação básica brasileira e registrando ainda presença de estratégias de ensino bastante alinhadas com o que o que Freire e Saviani, citados acima, chamaram de Pedagogias Tradicionais. Trabalhos como os de Leahy-Dios (2000; 2001), Santos (2003), Martins (In: BUZEN, MENDONÇA 2006) constituem alguns exemplos - dentre muitos que poderiam ser elencados - de reflexões que apontam para essa realidade ainda recorrente nas escolas de ensino secundário do país. 
Nesse cenário, Ensino da literatura, portanto, constitui uma expressão que ainda carrega as marcas que o termo ensino adquiriu em um universo escolar no qual, entre outros traços característicos, o professor ocupava uma centralidade inconteste e indiscutível na trans-mis-são do saber sobre a literatura acumulado entre gerações. Trata-se, sem dúvidas, de um cenário que se encontra em completa implosão nesses nossos tempos em que as chamadas fontes do saber se acham à palma da mão, em dispositivos tecnológicos cada vez mais acessíveis. Dizendo de outro modo, quando recolhidos e analisados depoimentos dos alunos de escolas públicas e particulares do Brasil, como feito em trabalhos como o de Santos (2003), ainda é perfeitamente possível constatar a ocorrência do ensino da literatura como algo que remete a um tempo em que a leitura do texto literário era uniderecionada pela visão do professor e/ou do teórico que o docente elegia como fundamentação, cabendo ao aluno/leitor apenas a possibilidade concordar com a aquela interpretação de um trecho ou texto do universo literário. Tem-se, ainda hoje, portanto, o emprego de práticas pedagógicas que são a expressão de um tempo em que uma leitura que discordasse da feita pelo professor ou pelo teórico por ele eleito era, necessariamente, uma leitura errada.

Hoje os tempos são outros. Tomada como produção de sentidos, conforme afirma Paulino et.al (2001), a leitura do texto literário tornou-se, em situação escolar, um exercício que envolve, além do próprio texto (ECO 1986; 1993), outros dois sujeitos que devem estar ativamente envolvidos nesse processo: o aluno e o professor, cada qual com suas histórias de vida e suas trajetórias de leitura (EVANGELISTA 2000; MELLO, 1998, 1999). Nesse contexto, conforme salienta Walty (In.: PAULINO; WALTY, 1994, p. 21), "ler é travar um duelo com o texto ou no texto enquanto campo de batalha, não com o objetivo de destruí-lo nem se deixando destruir por ele; mas com o objetivo de dialogar, de interagir, de promover trocas".

Nos termos de Umberto Eco:

[...] o texto está, pois, entremeado de espaços brancos, de interstícios a serem preenchidos, e quem o emitiu previa que esses espaços e interstícios seriam preenchidos e os deixou em branco por duas razões. Antes de tudo, porque um texto é um mecanismo preguiçoso (ou econômico) que vive da valorização de sentido que o destinatário ali introduziu [...]. Em segundo lugar, porque [...] o texto quer deixar ao leitor a iniciativa interpretativa, embora costume ser interpretado com uma margem suficiente de univocidade. Todo texto quer alguém que o ajude a funcionar. (ECO, 2008, p.37)

Diferentemente da cultura do ensino da literatura herdada de concepções de ensino de Língua Portuguesa afeitas ao entendimento original do termo ensino, sabemos, que esse "alguém que ajude o texto [literário, para o que nos interessa] a funcionar", é, hoje, tanto o professor quanto o aluno. Nesse sentido, portanto, ler um texto literário em contexto escolar de promoção de aprendizagens significativas se torna um trabalho de intensa negociação dos sentidos do texto, do significado desse ou daquele termo, dessa ou daquela construção, dessa ou daquela interlocução ou recuperação de ideias, de fatos, de informações... implicando a interferência de uma série infinita de fatores que passam não só pelas condições de produção e de recepção da obra literária, mas também de fatores outros, associados às trajetórias de professores e alunos que 
se encontram no momento de sua abordagem na sala de aula. Tem-se, assim, no trato do texto literário em contexto escolar, um clima de "confronto" e de "negociações" que, em tudo, tende a se intensificar no ensino médio, considerando que o aluno potencial desse nível de ensino é um jovem já com algum conhecimento de mundo e, também, do universo literário. Universo este, aliás, que, como muito bem sistematiza Kirchof (2016), há tempos transcendeu os limites do livro em formato convencional, ao qual ainda um grande número de "professores de literatura" que atuam nas aulas de Língua Portuguesa das escolas de nível médio do Brasil ainda se mantém preso.

Essas concepções e operações defendidas nos dois últimos parágrafos quanto à abordagem do texto literário não se distanciam, como se percebe, do que Freire e Saviani, cada qual a seu modo, defendem ser função da escola. No entanto, dada a cristalização de práticas pedagógicas desalinhadas com essas perspectivas no seio da expressão ensino de literatura que circula pelas escolas secundárias do país, parece-nos mais adequado denominar a abordagem do texto literário nas aulas de Língua Portuguesa do Ensino Médio em tempos atuais por trabalho com a leitura literária do que por ensino da literatura. E se trata de uma mudança que, a nosso ver, não é meramente de ordem semântica, uma vez que se pressupõe, minimamente, algumas rupturas básicas. Uma primeira delas com a noção perniciosa de que os alunos, em especial os do Ensino Médio, não têm condições intelectuais de participar, de forma ativa, na produção dos sentidos de um texto literário. Uma segunda, em consonância com os estudos de Mello (1999) e Giasson (2000; 2003), com a noção de que a escrita é sinônimo de ação por excelência e, a leitura, um exercício de passividade, que não demanda esforço.

Sendo uma expressão com certa presença em publicações e pesquisas que tomam como objeto a abordagem do texto literário, trabalho com a leitura literária constitui um sintagma que emprega um termo - trabalho - em torno do qual a tradição filosófica ocidental tem produzido uma considerável luta por atribuição de sentido (Cf. ABBAGNANO, 2003, p. 964-966). Para o que nos interessa neste texto, parece-nos mais acertado compreender a acepção de trabalho na expressão trabalho com a leitura literária mais afeita aos pontos de vista que Hegel tinha deste conceito do que aos entendimentos de Marx, para os quais tendemos a pender quando lidamos com este conceito.

Em suas reflexões sobre trabalho - às quais Marx faz certas críticas, mas não ignora - Hegel não toma o trabalho como mera satisfação de necessidade imediatas/individuais do homem. Para ele, por meio do trabalho se forma a consciência pessoal e social do ser humano por meio a realização de uma atividade a que é atribuído um significado. Assim, segundo Hegel (1971), por meio do seu operar, o homem sai de um ciclo repetitivo da natureza, transformando, alterando, redirecionando objetos em instrumentos por meio dos quais também produz cultura e cria uma história coletiva que se expressa por meio da linguagem. Nesse sentido, o trabalho é tomado como atividade pensada e intencional, como uma ação com uma finalidade social, política e duradoura que se opõe, portanto, a um fazer bruto, cego, imediato e sem finalidade. Para Hegel (1971, p.90), ao lidar com a natureza por meio dos seus processos laborais, o homem desenvolve sua consciência, sua cultura, seu encontro consigo e com os outros, sua linguagem e seu mundo social. Uma abordagem do texto literário alinhada com as demandas atuais da escolarização regular deve, assim, acionar 
práticas pedagógicas que, em última instância, promovam um trabalho com a leitura literária que proporcione ao leitor/aprendiz esse deslocamento que, segundo Hegel, é resultado do trabalho humano.

\section{MAPEANDO ALGUNS EXCESSOS QUE AFASTAM LEITORES JOVENS DO TEXTO LITERÁRIO NAS AULAS DE LÍNGUA PORTUGUESA DO ENSINO MÉDIO}

Para além das rupturas mencionadas ao final do tópico anterior, faz-se necessária, por parte dos docentes, a adoção de estratégias que permitam a superação dos muitos excessos que, na trajetória da escolarização da literatura no Brasil, em particular no ensino médio, vêm contribuindo para o distanciamento que se verifica entre o leitor jovem e o texto literário no espaço escolar e, em muitos casos, fora dele.

O primeiro e mais persistente desses excessos está na propensão das "aulas de literatura" do ensino médio para aquilo que, estudando o contexto do ensino secundário português, Cardoso-Bernardes chamou de presença do historicismo ou do retoricismo (In. DIONÍSIO e CASTRO, 2005). Tem-se, assim, a despeito da forte crítica empreendida por estudiosos do assunto no Brasil (p.ex. LEAHY, 2004; LEAHY-DIOS, 2001; MARTINS In: BUZEN, MENDONÇA 2006), ainda uma ocorrência de aulas em que professores dão mais importância à história de um autor ou de uma obra que ao exercício de leitura efetiva do texto. Nesse sentido, não é raro ainda encontrarmos aulas, livros e apostilas fundamentados na perspectiva historicista da abordagem da literatura, sobretudo na visão positivista de progressão de períodos literários.

Um segundo desses excessos, cujo efeito sobre as "aulas de literatura" do Ensino Médio também se faz devastador está na a falta de um filtro, por parte dos professores, entre o que se viu na formação universitária e o que se ensina na educação secundária (AGUIAR E SILVA, 1998-9). Evidência disso é que ainda se veem, em salas de aulas de língua materna da escola de nível médio brasileira, a mera transposição das densas análises realizadas em aulas universitárias para as do ensino médio. Transposição esta muitas vezes ancorada por livros didáticos, apostilas e provas de vestibular de influentes universidades brasileiras, os quais recorrem a trechos de respeitados autores de Teoria Literária nacionais e estrangeiros para fomentar o aluno a realizar análises de trechos de obras em processos seletivos que possuem as famosas listas de livros de leitura obrigatória que orientam, por sua vez, a construção dos programas escolares de literatura.

Diretamente ligado a esse segundo excesso a que nos referimos no parágrafo anterior, um terceiro está na desarticulação entre o conhecimento acumulado sobre a literatura e as necessidades reais da transmissão desse conhecimento, assunto cuja discussão feita no segundo capítulo da obra Portos de Passagem (GERALDI, 1997), a despeito do seu tempo de publicação, continua atual. Sinal da persistência desse terceiro excesso é que, nas salas de aula do ensino médio, muitos são os professores que não conseguem fazer uma distinção necessária entre o conteúdo do ensino e o conteúdo científico produzido sobre a literatura, fazendo com que um sem número de informações dispensáveis para o leitor do ensino médio seja insistentemente cobrado dos estudantes.

Um quarto excesso que tem colocado "a literatura em perigo" (TODOROV, 2009) no contexto de escolarização do saber literário se relaciona com os 
descuidos na apresentação da literatura ao público jovem (TODOROV, 2009). Cada vez mais, esse é um público cuja convivência com centenas de dispositivos eletroeletrônicos de Tecnologias de Informação e Comunicação (TIC) exige do professor artifícios pedagógicos que tornem as "aulas de literatura" mais interativas, dialogadas e problematizadoras da realidade em que se inscrevem os leitores jovens. Ação esta que exige do docente inclusive a aceitação de que dispositivos como o telefone móvel - sobretudo quando com acesso à internet devem ser tomados como parte integrante da aula em que se aborda o texto literário, permitindo que, com o uso deles, possam ser realizadas leituras individuais e coletivas, edição, reescrita, ilustração, discussão de temas atuais, entre outras infinitas possibilidades geradas pelas TIC.

Em uma obra de breve extensão, mas de leitura indispensável para o formador de leitores críticos de textos literários, Compagnon (2009) alerta, entre outros aspectos, para o que consideramos um quinto excesso que tem contribuído para o afastamento entre o texto literário e o leitor jovem: a escassez de espaço para o literário nas sociedades contemporâneas. A despeito dos avanços no campo da pedagogia da leitura e das estratégias de promoção da aprendizagem em espaços escolares, nota-se que, quando se trata do ensino médio no Brasil, a literatura, sobretudo a canônica, não transcende o enclausuramento das velhas estantes das bibliotecas escolares, não sendo objeto - como se vê no Ensino Fundamental do país - de projetos e atividades de leitura que ocupem todos os espaços escolares e não escolares das comunidades.

Finalmente, e não menos importante, um sexto excesso que contribui sobremaneira para a difícil relação entre o leitor jovem e a literatura nas aulas de Língua Portuguesa do Ensino Médio está na permanência dos velhos modelos de docência para abordagem do texto literário, os quais se perpetuam de geração para geração de professores, sem um mínimo de atualização. Alimentados pela falta de inovação e pela pouca inventividade das aulas oferecidas aos universitários de cursos em formação inicial de professores de Letras e pelas fórmulas cristalizadas nos livros didáticos e apostilas adotados por escolas de todo o país, esses modelos de "aula de literatura" perpetuam estratégias de ensino que se repetem há décadas no país. Tem-se, assim, a retomada constante de velhos "planos de aula" em que os mesmos trechos das mesmas obras dos mesmos autores são colocados lado a lado com as mesmas canções da Bossa Nova e da Jovem Guarda, com os mesmos trechos de filmes do Cinema Novo, com as mesmas pinturas e esculturas de sempre... sendo que quase tudo desse "sempre" não fez e não faz parte do universo do jovem que, sobretudo nas escolas públicas, possui outras referências culturais e não entende por que tais referências são completamente desconsideradas pela escola secundária que ele frequenta.

\section{CONCLUSÃO}

Como se buscou evidenciar neste texto, segundo os documentos reguladores dos anos finais da educação básica publicados entre o final do século XX e o início do século XXI no Brasil, o sujeito docente de Língua Portuguesa para o trabalho com a leitura literária que deve ocupar uma centralidade como agente de uma mudança na educação formal é o formador de leitores críticos de textos literários. 
Ao contrário do que se possa pensar hoje em dia, passadas quase duas décadas do aparecimento dos Parâmetros Curriculares Nacionais que permitiram a sua emergência, o formador de leitores críticos de textos literários ainda não é uma figura recorrente nas aulas de Língua Portuguesa oferecidas aos jovens que cursam ensino médio no país. Muitos professores de língua materna desse nível de ensino sequer têm conhecimento do que deles é demandado quando da abordagem do texto literário em contexto escolarizado nos anos finais da educação básica. As razões para tanto são de naturezas diversas e, até certo ponto, algo inerente a um país de dimensões vastas com um sistema educacional que sofre cotidianamente os efeitos dessa vastidão e das incontáveis fragilidades a que estudantes - em particular os jovens do ensino médio - estão expostos na sociedade brasileira.

O leitor deste ensaio, com certeza, sairá de sua leitura com pelo menos um incômodo: o de não ter encontrado aqui um receituário pedagógico de práticas docentes para abordar "de forma correta" o texto literário em sala de aula. Optamos, como anunciado no início desta reflexão, por um caminho diferente: o de apontar, para esse leitor, o que ele não deve fazer, caso queira estar alinhado com os comportamentos desejáveis de um formador de leitores críticos de textos literários nas aulas de língua materna do Ensino Médio.

Acreditamos que, com a adoção desta estratégia, o texto poderá cumprir a promessa que ele projeta no título: a de estar a serviço da provocação de uma conversa entre interessados na formação de formadores de leitores para atuarem no Ensino Médio. Que essa conversa se inicie por uma crítica a esse texto, não é um problema. O importante é que ela comece e que os argumentos aqui expostos estimulem formadores de formadores de leitores a sugerirem o que poderia ser feito, consideradas as realidades de cada escola, de cada sujeito leitor docente e discente, para que o distanciamento entre o leitor jovem e o texto literário possa ser minimamente encurtado. Acreditamos que este texto fornece boas diretrizes para isso. 


\title{
Talking about the challenges of the current formation of readers of literary texts in brazilian high schools
}

\begin{abstract}
In this essay, we start with the presentation of the context of the reorientations on the approach of the literary text in the discourses regulating the teaching of Portuguese Language of the Brazilian High School of the 1990s, to treat emergence of the trainer of critical readers of literary texts, position of subject to be occupied by professors of Portuguese Language of the current Brazilian High School. In the sequence, the argument is defended that the denomination teaching of literature does not align with the current demands for the approach of the literary text in the final years of the basic education of Brazil, betting on the denomination work with the literary reading. Finally, in a last topic, we list, on the basis of some authors whose full reading this text does not dispense, six excesses that, in our view, contribute to distancing, in the brazilian high school, the young reader of the literary text. It is a text whose central objective is to present, in an accessible way, a panel of the tensions that today cross the approach of the literary text in the classroom so as to stimulate discussions in continuing education courses of Portuguese Language teachers for the work with literary reading in Brazilian High School.
\end{abstract}

KEY-WORDS: Teacher Education. Portuguese Language. Training of Readers. Brazilian High School. 


\section{NOTA}

${ }^{1}$ Não nos ateremos, neste texto, à discussão atual acerca da Base Nacional Curricular Comum que vem sendo preparada pelas instâncias governamentais, com objetivos parecidos aos de quando do surgimento dos PCN. Do mesmo modo, não adentraremos nas reflexões acerca da Reforma do Ensino Médio que vêm, não sem razões, causando embates vários entre grupos diversos do setor educacional no país. Entendemos que as questões sobre a abordagem do texto literário apontadas neste ensaio são urgentes a quaisquer modelos de escolas de nível médio a serem adotados no Brasil hoje. No entanto, cabe-nos chamar a atenção para o fato de que as argumentações pró e contra as mudanças na educação formal de nível médio em discussão neste momento no país não estão tão distantes das alegações elencadas por Marinho (2007) na presente citação.

${ }^{2}$ Segundo os documentos oficiais citados neste texto, o professor se revela um leitor não preconceituoso quando tem abertura para ler/trabalhar/dialogar com todo o tipo de obra literária e não literária, não se restringindo apenas àquelas consagradas pelo cânone escolar. (BRASIL, 2006; SANTOS, 2011)

\section{REFERÊNCIAS}

ABBAGNANO, Nicola. Dicionário de Filosofia. 4.ed. Tradução de Alfredo Bosi. São Paulo: Martins Fontes: 2003.

AGUIAR E SILVA, Vítor. Tese sobre o ensino do texto literário na aula de português. Diacrítica. Revista do Centro de Estudos Humanísticos. n.13-14. Braga: Universidade do Minho, 1998/1999. p. 23-31.

AUSUBEL, David P., NOVAK, Joseph D., HANESIAN, Helen. Psicologia educacional. Tradução Eva Nick. Rio de Janeiro: Interamericana , 1980.

BACHA, Edmar Lisboa; SCHWARTZMAN, Simon (Orgs). Brasil: a nova agenda social. Rio de Janeiro: LTC, 2011.

BERTUCCI BARBOSA, J.; VIEIRA BARBOSA, M. (Orgs). Leitura e Mediação: reflexões sobre a formação do professor. Campinas, SP: Mercado das Letras, 2013.

BRASIL. Ministério da Educação. Secretaria de Educação Básica. PCN+ Ensino Médio: Orientações Educacionais Complementares aos Parâmetros Curriculares Nacionais. Linguagens, Códigos e suas Tecnologias. Brasília: Ministério da Educação, 2002. 
BRASIL. Ministério da Educação. Secretaria de Educação Média e Tecnológica. Parâmetros Curriculares Nacionais: Ensino Médio. Brasília: Ministério da Educação, 1999.

BRASIL. Ministério da Educação. Orientações curriculares para o ensino médio. Linguagens, códigos e suas tecnologias / Secretaria de Educação Básica. - Brasília: Ministério da Educação, Secretaria de Educação Básica, 2006.

CARDOSO BERNARDES, José Augusto. A literatura no ensino secundário: excessos, expiações e caminhos novos. In: DIONÍSIO, Maria de Lourdes; CASTRO, Rui Vieira de (Orgs.). O português nas escolas. Ensaios sobre a língua e a literatura no ensino secundário. Coimbra: Almedina, 2005. p. 93-131.

COMPAGNON, Antoine. Literatura para quê? Tradução de Laura Taddei Brandinni. Belo Horizonte: Editora da UFMG, 2009.

CUNHA, Antônio Geraldo da. Dicionário etimológico Nova Fronteira da Língua Portuguesa. 2. ed. Rio de Janeiro: Nova Fronteira, 2001.

CURY, C. R. J. "Os Parâmetros Curriculares Nacionais e o Ensino Fundamental”. Revista Brasileira de Educação, n.2, mai/jun/jul/ago, 1996. p.4-17.

CURY, C. R. J. A educação básica no Brasil. Educação e Sociedade: Revista de Ciência da Educação. Centro de Estudos Educação e Sociedade - v.23, n.80. São Paulo: Cortez; Campinas: CEDES, 2002. p. 169-201.

DUARTE, Ronaldo Alves. [Re]Tratando a família: reflexos e reflexões sobre família e saúde mental. 2008. 175f. Dissertação (Mestrado em Educação, Cultura e Organizações Sociais). Fundação Educacional de Divinópolis. Universidade do Estado de Minas Gerais. Divinópolis/MG, 2008.

ECO, Umberto. Lector in fábula. Tradução de Atílio Cancian. São Paulo: Perpectiva, 1986.

ECO, Umberto. Interpretação e superinterpretação. São Paulo: Martins Fontes, 1993.

ECO, Umberto. Os limites da interpretação. 2.ed. Tradução de Pérola de Carvalho. São Paulo: Perspectiva, 2008. 
2000. 294 f. Tese (Doutorado em Educação) - Faculdade de Educação, Universidade Federal de Minas Gerais, Belo Horizonte, 2000.

FREIRE, P. Pedagogia do Oprimido. Rio de Janeiro: Paz e Terra, 1987.

GERALDI, João Wanderley. Portos de passagem. 4.ed. São Paulo: Martins Fontes, 1997.

GIASSON, Jocelyne. A compreensão na leitura. Tradução de Maria José Frias. Porto: Edições Asa, 2000.

GIASSON, Joycelyne. La Lecture: de La théorie à la pratique. Adaptation réalisée par Tessa Escoyez. 2.ed. Bruxelles: Gaëtan Morin Editeur; 2004; Montreal: De Boeck, 2003.

GIROUX, Henry. Os professores como intelectuais. Porto Alegre: Artes Médicas, 1997.

HEGEL, G. W. F. Filosofia dello spirito jenese. Editado por Cantillo Bari: Laterza, 1971.

KOCH, Igedore G. V. Desvendando os segredos do texto. 6.ed. São Paulo: Cortez, 2009.

KIRCHOF, Edgar Roberto. Como ler os textos literários na era da cultura digital? Revista Estudos de Literatura Brasileira Contemporânea. N. 47, p. 203-228, jan./jun. 2016.

LEAHY-DIOS, Cyana. Educação literária como metáfora social: desvios e rumos. Niterói: EDUFF, 2000.

LEAHY-DIOS, Cyana. Língua e literatura: Uma questão de educação?. Campinas, SP: Papirus, 2001.

LEAHY, Cyana. A educação literária e as políticas oficiais. In: PAULINO, Graça; COSSON, Rildo (Orgs.). Leitura literária: a mediação escolar. Belo Horizonte: Faculdade de Letras da UFMG, 2004.

MARTINS, Ivanda. "A literatura no ensino médio: quais os desafios do professor?”. In: BUZEN, Clécio; MENDONÇA, Márcia (Orgs). Português no ensino médio e formação do professor. São Paulo: Parábola editorial, 2006. p. 83-102. 
MARINHO, Marildes. Currículos da escola brasileira: elementos para uma análise discursiva. Revista Portuguesa de Educação, Braga/Portugal, v. 20(1), p. 163-189, Jan. 2007.

MELLO, Cristina. 0 ensino da literatura e a problemática dos gêneros literários. Coimbra: Almedina, 1998.

MELLO, Cristina. Leitura e memória literária. In.: MELLO, Cristina (Coord.). I Jornadas científico-pedagógicas de português. Coimbra: Almedina, 1999. p.219228.

MOREIRA, C.E. Criticidade. IN: REDIN, E.;STRECK, D.R.;ZITKOSKI, J.J. (Org.). Dicionário Paulo Freire. 2 ed.Belo Horizonte: Autêntica, 2010

MOREIRA, Marco A., MASINI, Elcie F. Salzano. Aprendizagem significativa: A teoria de David Ausubel. São Paulo: Moraes, 1982.

PAULINO, Graça; WALTY, Ivete; FONSECA, Maria Nazareth; CURY, Maria Zilda. Tipos de textos, modos de leitura. Belo Horizonte: Formato Editorial, 2001.

SANTOS, Rodrigo Alves dos. Do professor de literatura ao formador de leitores críticos de textos literários: um estudo sobre a (re)invenção do professor de língua portuguesa para o trabalho com a leitura literária no ensino médio. 199f. Tese de doutorado (Doutorado em Educação) - Faculdade de Educação Universidade Federal de Minas Gerais (MG), 2009.

SANTOS, Rodrigo Alves dos. Do rumor ao valor: reflexos e reflexões sobre a aula de literatura. 2003. 141f. Dissertação (Mestrado em Ciências e Práticas Educativas) - Universidade de Franca, Franca (SP), 2003.

SANTOS, Rodrigo Alves dos. Conhecendo o perfil do jovem demandado pelo discurso oficial sobre o "novo" ensino médio. In.: CARVALHO, Carlos Frederico Vaz de; FRAGA, Fernando Caramuru Bastos; ROSA, José Henrique Alves; ARÃO, Lilian Aparecida (Coord). Dez olhares sobre juventude e cultura. Belo Horizonte: Fundação Guimarães Rosa, 2011. p.75-85

SANTOS, Rodrigo Alves dos. O caráter continuísta do discurso oficial sobre configuração de um sujeito docente para o trabalho com a leitura literária no ensino médio do século XXI. Revista Remate de Males (34-2), Jul/Dez (2014). Campinas, SP. p.421-441. 
SAVIANI, Dermeval. Escola e democracia: teorias da educação, curvatura da vara, onze teses sobre a educação política. 32 ed. Campinas, São Paulo, Autores Associados, 1999.

TODOROV, Tzvetan. A literatura em perigo. Tradução de Caio Meira. Rio de Janeiro: DIFEL, 2009.

UCHOA, Carlos Eduardo F. A linguística e o ensino de português. In: Cadernos de Letras, n. 2. Niterói: UFF/Instituto de Letras, 1991.

Recebido: 30 abr. 2017

Aprovado: 08 set. 2017

DOI: $10.3895 /$ rl.v19n26.5863

Como citar: SANTOS, Rodrigo Alves dos. Elementos para começar uma conversa sobre a formação de formadores de leitores críticos de textos literários para atuação no Ensino Médio. R. Letras, Curitiba, v. 19, n. 26, p. 34-52, set. 2017. Disponível em: <https://periodicos.utfpr.edu.br/rl>. Acesso em: XXX.

Direito autoral: Este artigo está licenciado sob os termos da Licença Creative Commons-Atribuição 4.0 Internacional. 